\title{
STRUCTURAL IDENTIFICATION OF DISTINCT INVERSIONS OF PLANAR KINEMATIC CHAINS
}

\author{
SANYAL SHUBHASHIS \\ Mechanical Engineering Department, \\ National Institute of Technology, Raipur (C.G.), India, 492010. \\ shubhashissanyal@ rediffmail.com
}

\begin{abstract}
Inversions are various structural possibilities of a kinematic chain. The number of inversions depends on the number of links of a kinematic chain. At the stage of structural synthesis, identification of distinct structural inversions of a particular type of kinematic chain is necessary. Various researchers have proposed methods for identification of distinct inversions. Present method based on Link joint connectivity is proposed to identify the distinct inversions of a planar kinematic chain. Method is tested successfully on single degree and multiple degree of freedom planar kinematic chains.
\end{abstract}

\begin{abstract}
ABSTRAK: Penyonsangan merupakan kebarangkalian pelbagai struktur suatu rangkaian kinematik. Jumlah songsangan bergantung kepada jumlah hubungan suatu rangkaian kinematik. Pada peringkat sintesis struktur, pengenalan songsangan struktur yang berbeza untuk suatu jenis rangkaian kinematik adalah perlu. Ramai penyelidik telah mencadangkan pelbagai kaedah pengenalan songsangan yang berbeza. Kaedah terkini berdasarkan hubungan kesambungan bersama telah dicadangkan untuk mengenalpasti songsangan yang berbeza dalam suatu satah rangkaian kinematik.
\end{abstract}

KEYWORDS: kinematic chains; links; joints; link joint connectivity; distinct inversions

\section{INTRODUCTION}

To generate the constrained relative motion, kinematic chains made up of links and joints are used. To get the above objective one of the links of the kinematic chain is fixed and thus the kinematic chain with a fixed link is known as a mechanism / linkage. The fixed link is also known as a frame link. Identification of a frame link is necessary because the input motion is provided at any of the joints attached with the frame link; vice versa the output motion is received from any of the joints attached with the frame link.

Inversion of a mechanism does not change the motions of its links relative to each other but does change their absolute motions. In case of a four link kinematic chain, four inversions are possible. However, all the inversions in case of four bar kinematic chains are structurally similar since all of them are binary. The case will be different for higher link chains, such as six link, eight link, and nine link chains and so on. In these cases the chains are made up of different type of links, binary, ternary, quaternary etc. The inversions in these cases will be structurally different, since the type of frame link will be different. For example, in case of six link Watt's Chain, Fig.1, through visual inspection only it is possible to identify that there are two distinct structural inversions, one by fixing any of the four binary link and one by fixing any one of the ternary link. In case of Stephenson's Six link Chain the number of distinct 
inversions are three. Identification of these distinct structural inversions is important at the stage of structural synthesis, since the motion characteristics will be different for different inversions and vice versa.

Various researchers have proposed methods for identification of distinct inversions. Manolescu [1] reported for the first time a total of 219 distinct mechanisms derived from nine link two degrees of freedom kinematic chains. Mruthyunjay [2] corrected the above and reported 71, 254 and 1834 distinct mechanisms for eight link single degree of freedom, nine link two degrees of freedom and ten link single degree of freedom kinematic chains. Mrythunjaya and Raghavan [3] used a modified characteristic polynomial for detecting distinct inversions. Ambekar and Agrawal [4] extended the min code approach to identify the inversions corresponding to the original kinematic chain. Patel and Rao [5] presented a method based on velocity graphs and motion transfer matrix. The hamming number technique of Rao and Raju [6] has the potential to disclose the distinct inversions. Chu Jin Kui and Cao Wei Qing [7] extended the link's adjacent chain table for detection of inversions. Yadav et. Al. [8] used a new invariant called Arranged Sequence of ModifiedTotal Distance Ranks of all the links (ASMTDRL) encorporating the degrees of links, degrees of freedom and types of joint of the kinematic chain to identify the distinct inversions. Sanyal et. al. [9] proposed a link link probability matrix based method. Fuzzy logic and loop based methods are also presented by Rao and his coworkers [10, 11, 12]. Srinath and Rao[13] presented a method based on corelation concept for detection of isomorphism among kinematic chains and their inversions. R. Simoni et. al. [14] presented a method based on group theory for enumeration of mechanisms. The symmetry of graphs is identified by a group of autoisomorphism and the set of vertices in the same equivalence class is used to identify the symmetrical links - since every kinematic chain can be presented by its graph. Ashok Dargar et. Al. [15] used link adjacency values - first and second to identify the distinct inversions. The method has the potential of identifying the isomorphic kinematic chains also. Bedi and Sanyal $[17,18]$ has presented Joint connectivity approach for detection of isomorphism and distinct inversions of planar kinematic chains. The method [18] proposed by them also identifies unique joints in a kinematic chain.

Many of the method proposed by earlier researchers, either does not incorporate direct determination of distinct inversions or are computationally complex and time taking. Based on the above literature a computationally simple but reliable method based on link joint connectivity table is proposed to identify the structurally distinct inversions of a kinematic chain.

Method based on connectivity of links at different level through different type of joints is proposed. Care has been taken to incorporate the structural details of the kinematic chain up to the last level of connectivity so as to identify the not only the isomorphism but also the distinct inversions of the kinematic chain. The method is applied successfully to single and multiple degrees of freedom kinematic chains. The results are validated through the earlier reported results for validation.

\section{METHOD}

Different type of links is attached with each other through different type of joints. Depending upon the difference in these connectivity's the kinematic chains differ from each 
other. In view of the above literature and in view of the fact that a method based on the accommodating the topological characteristics ofkinematic chain up-to the last level, the present work is proposed for identification of distinct inversions of a planar kinematic chain with revolute joints. A unique link joint connectivity table representing the kinematic chain is proposed by author [16]. The elements of the table represent the number of connecting links and the type of joint through which the connectivity is established. The elements are tabulated up-to the last level so as to incorporate all the topological characteristics of the kinematic chain.

The Link - Joint connectivity Table (LJCT) and the scheme generated thereof, is proposed for detection of distinct inversions of a kinematic chain. The method is introduced through its application to Watt's and Stephenson's six link planar kinematic chains (Fig. 1).
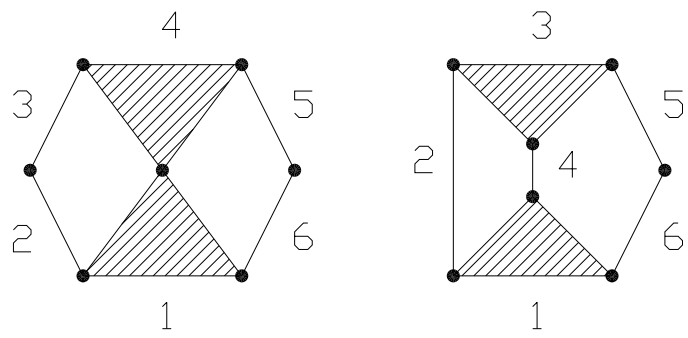

Fig. 1: Watt's and Stephenson's six link kinematic chain.

\subsection{Link - Joint Connectivity Table (LJCT)}

Link joint connectivity are prepared (Tables 1 and 2) for Watt's and Stephenson's six link chains. The element 2, 4, 6 in Table 1, for the first link shows the direct connectivity of link1 with three links namely link 2, 4 and 6 (Fig. 1). This also states that link1 is a ternary link. Further the element in the second row for the first link shows that the connectivity of link 1 with link 2, 4 and 6 is through joint type BT (a binary ternary joint), TT (a ternary - ternary joint) and a BT (a binary ternary joint). The connectivity of further level i.e. level 2 and 3 is also tabulated for link1. A code is generated which represent the type of the parent link and its number of connections up to the last level. For example, code $\mathrm{T}(3,2)$ for link 1 represent that the link is a ternary link and it is connected to 3 links at first level and 2 links at second level. In this way theconnectivity of all links with other links at all possible levels and its codes are tabulated in the LJCT for Watt's and Stephenson's six link chain, Table 1 and Table 2.

\subsection{Link Joint Connectivity Schemes (LJCS)}

For ease of representation a scheme generated from the LJCT is proposed. The scheme arranges the codes of the respective links in order. The schemes generated for the Watt's and Stephenson's six link chains are shown below.

$\left[4 \mathrm{~B}_{1}(2,2,1), 2 \mathrm{~T}_{1}(3,2)\right]$

$\left[2 \mathrm{~B}_{1}(2,3), 2 \mathrm{~B}_{2}(2,3), 2 \mathrm{~T}_{1}(3,2)\right]$ 
Table 1: Link - Joint Connectivity Table for Watt's Six Link Chain.

\begin{tabular}{|c|c|c|c|c|}
\hline $\begin{array}{l}\text { Link } \\
\text { No. }\end{array}$ & Level 1 & Level 2 & Level 3 & Code \\
\hline \multirow[t]{2}{*}{1} & $2,4,6$ & 3,5 & - & $\mathrm{T}(3,2)$ \\
\hline & BT,TT,BT & $\mathrm{BB} / \mathrm{BT}, \mathrm{BB} / \mathrm{BT}$ & - & $\mathrm{T} 1$ \\
\hline \multirow[t]{2}{*}{2} & 1,3 & 4,6 & 5 & $\mathrm{~B}(2,2,1)$ \\
\hline & $\mathrm{BT}, \mathrm{BB}$ & $\mathrm{BT} / \mathrm{TT}, \mathrm{BT}$ & $\mathrm{BB} / \mathrm{BT}$ & B1 \\
\hline \multirow[t]{2}{*}{3} & 2,4 & 1,5 & 6 & $\mathrm{~B}(2,2,1)$ \\
\hline & $\mathrm{BB}, \mathrm{BT}$ & $\mathrm{BT} / \mathrm{TT}, \mathrm{BT}$ & $\mathrm{BB} / \mathrm{BT}$ & B1 \\
\hline \multirow[t]{2}{*}{4} & $1,3,5$ & 2,6 & - & $\mathrm{T}(3,2)$ \\
\hline & TT,BT,BT & $\mathrm{BB} / \mathrm{BT}, \mathrm{BB} / \mathrm{BT}$ & - & $\mathrm{T} 1$ \\
\hline \multirow[t]{2}{*}{5} & 4,6 & 3,1 & 2 & $\mathrm{~B}(2,2,1)$ \\
\hline & BT,BB & $\mathrm{BT}, \mathrm{TT} / \mathrm{BT}$ & $\mathrm{BB} / \mathrm{BT}$ & $\mathrm{B} 1$ \\
\hline \multirow[t]{2}{*}{6} & 1,5 & 2,4 & 3 & $\mathrm{~B}(2,2,1)$ \\
\hline & $\mathrm{BT}, \mathrm{BB}$ & TT,BT/TT & $\mathrm{BB} / \mathrm{BT}$ & B1 \\
\hline
\end{tabular}

\begin{tabular}{|c|c|c|c|}
\hline Link No. & Level 1 & Level 2 & Code \\
\hline 1 & $2,4,6$ & 3,5 & $\mathrm{~T}(3,2)$ \\
\hline & BT,BT,BT & BT,BB & T1 \\
\hline 2 & 1,3 & $4,5,6$ & B(2,3) \\
\hline & BT,BT & BT,BT,BT & B1 \\
\hline 3 & $2,4,5$ & 1,6 & $\mathrm{~T}(3,2)$ \\
\hline & $\mathrm{BT}, \mathrm{BT}, \mathrm{BT}$ & $\mathrm{BT}, \mathrm{BB}$ & $\mathrm{T} 1$ \\
\hline 4 & 1,3 & $2,5,6$ & $\mathrm{~B}(2,3)$ \\
\hline 5 & $\mathrm{BT}, \mathrm{BT}$ & $\mathrm{BT, \textrm {BT } , \mathrm { BT }}$ & $\mathrm{B} 1$ \\
\hline & 3,6 & $1,4,2$ & $\mathrm{~B}(2,3)$ \\
\hline 6 & 1,5 & $2,4,3$ & $\mathrm{~B}(2,3)$ \\
\hline & $\mathrm{BT}, \mathrm{BB}$ & $\mathrm{BT}, \mathrm{BT}, \mathrm{BT}$ & $\mathrm{B} 2$ \\
\hline
\end{tabular}

\subsection{Isomorphic Chains}

"Two kinematic chains will be non - isomorphic if their schemes generated from their link joint connectivity tables are different".

\subsection{Distinct Inversions:}

"Links having dissimilar codes for a kinematic chain in the Link Joint connectivity Table will be structurally different and will be identified as structurally distinct inversions".

From the two schemes generated following can be concluded:

1. It is obvious that though both the chains are having four binary and two ternary links, they are different due to their topological connectivity's with different links at different levels, i.e. they are non -isomorphic chains.

2. Watt's chain (Fig. 1), has two structurally distinct inversions, Watt's Inversion 1, one binary link - any of the four binary link with similar code and similar type of joints at the two levels, and Watt's Inversion II, one ternary - any of the two ternary with similar topological characteristics at all levels.

3. Stephenson's Chain, has three structurally distinct inversions, one binary (either of the links 2 or 4), second binary (either of the links 5 or 6) and one ternary (either of the links 1 or 3), respectively Stephenson's I, II and III (Fig. 2). 


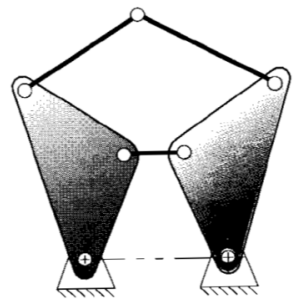

(a) Stephenson's sixbar inversion I

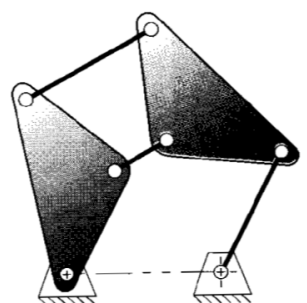

(b) Stephenson's sixbar inversion

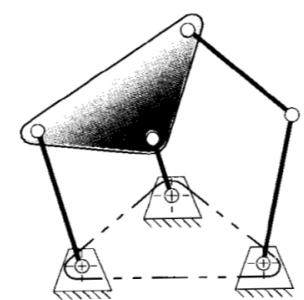

(c) Stephenson's sixbar inversion III

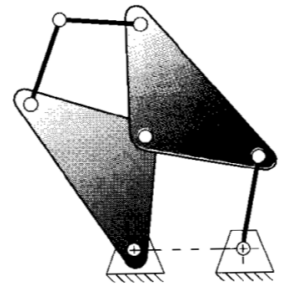

(d) Watt's sixbar inversion

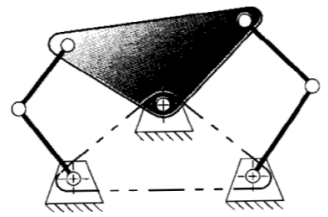

(e) Watt's sixbar inversion II

Fig. 2: Inversion's of Watt's and Stephenson's kinematic chain.
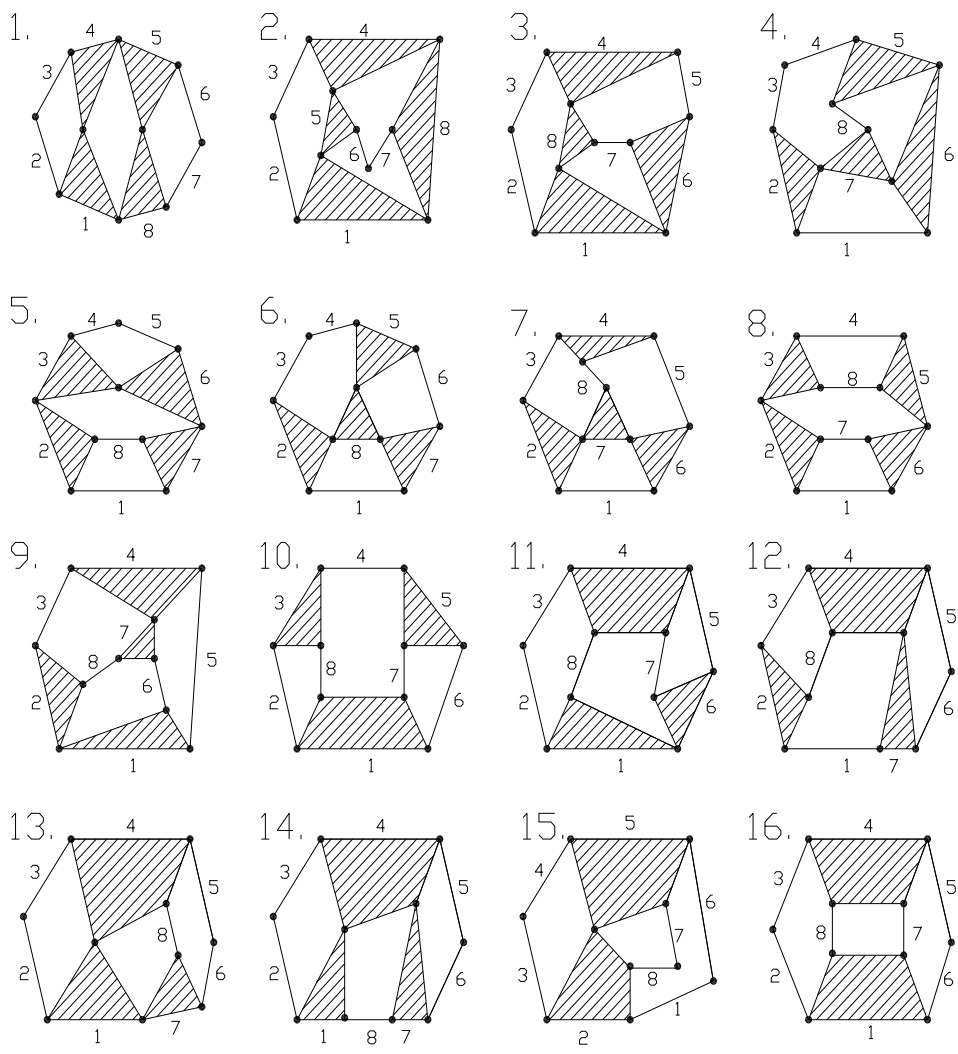

Fig. 3: Eight link single degree of freedom non-isomorphic planar kinematic chains. 


\subsection{Applications}

The method is applied to single degree and multiple degrees of freedom kinematic chains successfully.

\subsubsection{Single Degree of Freedom Kinematic Chains}

The method is applied to six links (Fig. 1) and eight link single degree of freedom planar kinematic chains (Fig. 3). Seventy one distinct inversions are determined for eight link chains (Table 3). The results obtained are verified with earlier results reported.

Table 3: Schemes for Eight Link Single Degree of Freedom Kinematic Chains.

\begin{tabular}{|c|c|c|c|}
\hline S.No. & Schemes & Inversions & Distinct Links \\
\hline 1 & {$\left[4 \mathrm{~B}_{1}(2,2,2,1), 4 \mathrm{~T}_{1}(3,3,1)\right]$} & 2 & 1 binary, 1 ternary \\
\hline 2 & {$\left[4 \mathrm{~B}_{1}(2,3,2), 4 \mathrm{~T}_{1}(3,4)\right]$} & 2 & 1 binary, 1 ternary \\
\hline 3 & $\begin{array}{l}{\left[\mathrm{B}_{1}(2,3,2), \mathrm{B}_{2}(2,3,2), \mathrm{B}_{3}(2,3,2), \mathrm{B}_{4}(2,4,1),\right.} \\
\left.\mathrm{T}_{1}(3,4), \mathrm{T}_{2}(3,4), \mathrm{T}_{3}(3,3,1), \mathrm{T}_{4}(3,4)\right]\end{array}$ & 8 & 4 binary, 4 ternary \\
\hline 4 & {$\left[2 \mathrm{~B}_{1}(2,3,2), 2 \mathrm{~B} 2(2,3,2), 2 \mathrm{~T}_{1}(3,3,1), 2 \mathrm{~T} 2(3,3,1)\right]$} & 4 & 2 binary, 2 ternary \\
\hline 5 & {$\left[2 \mathrm{~B}_{1}(2,3,2), 2 \mathrm{~B}_{2}(2,2,3), 2 \mathrm{~T}_{1}(3,3,1), 2 \mathrm{~T}_{2}(3,4)\right]$} & 4 & 2 binary, 2 ternary \\
\hline 6 & $\begin{array}{l}{\left[2 \mathrm{~B}_{1}(2,3,2), 2 \mathrm{~B}_{2}(2,3,2), 2 \mathrm{~T}_{1}(3,3,1), \mathrm{T}_{2}(3,2,2),\right.} \\
\left.\mathrm{T}_{3}(3,4)\right]\end{array}$ & 5 & 2 binary, 3 ternary \\
\hline 7 & $\begin{array}{l}{\left[\mathrm{B}_{1}(2,3,2), 2 \mathrm{~B}_{2}(2,4,1), \mathrm{B}_{3}(2,4,1), 2 \mathrm{~T}_{1,2(} 3,3,1\right),} \\
\left.\mathrm{T}_{3}(3,3,1), \mathrm{T}_{4}(3,4)\right]\end{array}$ & 6 & 3 binary, 3 ternary \\
\hline 8 & {$\left[4 \mathrm{~B}_{1}(2,3,2), 4 \mathrm{~T}_{1}(3,3,1)\right]$} & 2 & 1 binary, 1 ternary \\
\hline 9 & {$\left[4 \mathrm{~B}_{1}(2,4,1), 4 \mathrm{~T}_{1}(3,4)\right]$} & 2 & 1 binary, 1 ternary \\
\hline 10 & {$\left[4 \mathrm{~B}_{1}(2,4,1), \mathrm{B}_{2}(2,4,1), 2 \mathrm{~T}_{1}(3,2,2), \mathrm{Q}_{1}(4,2,1)\right]$} & 4 & 2 binary, 1 ternary, 1 quaternary \\
\hline 11 & $\begin{array}{l}{\left[\mathrm{B}_{1}(2,3,2), \mathrm{B}_{2}(2,4,1), 2 \mathrm{~B}_{3}(2,4,1), \mathrm{B}_{4}(2,5),\right.} \\
\left.\mathrm{T}_{1}(3,4), \mathrm{T}_{2}(3,3,1), \mathrm{Q}_{1}(4,3)\right]\end{array}$ & 7 & 4 binary, 2 ternary, 1 quaternary \\
\hline 12 & $\begin{array}{l}{\left[\mathrm{B}_{1}(2,2,3), \mathrm{B}_{2}(2,3,2), 2 \mathrm{~B}_{3}(2,4,1), \mathrm{B}_{4}(2,4,1)\right.} \\
\left.\mathrm{T}_{1}(3,2,2), \mathrm{T}_{2}(3,4), \mathrm{Q}_{1}(4,3)\right]\end{array}$ & 7 & 4 binary, 2 ternary, 1 quaternary \\
\hline 13 & $\begin{array}{l}{\left[\mathrm{B}_{1}(2,2,3), \mathrm{B}_{2}(2,3,2), \mathrm{B}_{3}(2,3,2), \mathrm{B}_{4}(2,4,1),\right.} \\
\left.\mathrm{B}_{5}(2,4,1), \mathrm{T}_{1}(3,3,1), \mathrm{T}_{2}(3,4), \mathrm{Q}_{1}(4,3)\right]\end{array}$ & 8 & 5 binary, 2 ternary, 1 quaternary \\
\hline 14 & $\begin{array}{l}{\left[2 \mathrm{~B}_{1}(2,2,2,1), 2 \mathrm{~B}_{2}(2,3,2), \mathrm{B}_{3}(2,3,2), 2 \mathrm{~T}_{1}(3,3,1),\right.} \\
\left.\mathrm{Q}_{1}(4,3)\right]\end{array}$ & 5 & 3 binary, 1 ternary, 1 quaternary \\
\hline 15 & {$\left[6 \mathrm{~B}_{1}(2,3,2), 2 \mathrm{Q}_{1}(4,3)\right]$} & 2 & 1 binary, 1 quaternary \\
\hline \multirow[t]{2}{*}{16} & {$\left[4 \mathrm{~B}_{1}(2,4,1), 2 \mathrm{~B}_{2}(2,5), 2 \mathrm{Q}_{1}(4,3)\right]$} & 3 & 2 binary, 1 quaternary \\
\hline & Total number of Inversions & 71 & \\
\hline
\end{tabular}




\subsubsection{Multiple Degrees of Freedom Kinematic Chains}

The method is also applied to nine link two degrees of freedom kinematic chains. It is found that of forty distinct nine link two degrees of freedom kinematic chains, a total of 254 structurally distinct inversions are available.

\section{CONCLUSIONS}

The method proposed is simple and exhaustive in nature since it includes the structural details of the kinematic chain up to the last level. The method has the potential of testing isomorphism and distinct inversions of kinematic chain. The method is applied successfully to single and multiple degree of freedom kinematic chains. The results obtained for distinct inversions matches with the earlier findings.

\section{ACKNOWLEDGEMENT}

Author is thankful to the institute for allowing the present work to be carried out.

\section{REFERENCES}

[1] Manolescu, N.I, 1973 " A method based on Baranov Trusses and using Graph theory to find the Set of Planar Jointed Kinematic Chains and Mechanisms", Mechanism and Machine Theory, Vol. 8, pp 3-22.

[2] T.S. Mruthyunjaya, 1984, A computerized methodology for structural synthesis of kinematic chains - Part I, II and III, Mechanism and Machine Theory, Vol. 14, pp. 487 - 530.

[3] T.S. Mruthyunjaya and M.R. Raghavan, 1984, Computer Aided analysis of the Structure of Kinematic Chain, Vol.19, No.3, pp 357 - 368.

[4] A.G. Ambekar and V.P. Agrawal, 1987, Canonical numbering of kinematic chains and isomorphism problem: Min code, Mechanism and Machine Theory, Vol. 22, No. 5, pp. 453 461.

[5] L. K. Patel and A.C. Rao, 1988, “ A Method for detection of Distinct Mechanisms of a Planar Kinematic Chain”, Transactions of CSME,Vol.12, No.1, pp 15 - 20.

[6] A.C. Rao and D. Varada Raju, 1991, Application of Hamming number technique to detect isomorphism among kinematic chains and inversions, Mechanism and Machine Theory, Vol. 26, No. 1 , pp. $55-75$.

[7] Chu Jin Kui and Cao Wei Qing, 1994, "Identification of Isomorphism among Kinematic Chains and Inversions using Link's Adjacent Chain Table", Vol. 29, No.1, pp 53 - 58.

[8] J.N.Yadav, C.R.Pratap and V.P.Agrawal, 1996, Computer Aided Detection of Isomorphism among Kinematic Chains and Mechanisms using the Concept of Modified Distance, pp 439 444.

[9] S. Sanyal, M. Choubey and A.C. Rao, 1997, Pseudo probabilistic approach to determine distinct inversions of kinematic chains, Trans. CSME, Vol. 21, No. 2.

[10] A.C.Rao, 1998, Topology based rating of kinematic chains and inversions using information theory, Mechanism and Machine Theory, Vol. 33, Issue 7, pp. 1055-1062.

[11] A.C. Rao, 2000, Application of fuzzy logic for the study of isomorphism, inversions, symmetry, parallelism and mobility in kinematic chains, Mechanism and Machine Theory, Vol. 35, pp 1104.

[12] A.C. Rao and V.V.N.R Prasad Raju Pathapati, 2000, Loop based detection of isomorphism among kinematic chains, inversions and type of freedom in multi degree of freedom chain, ASME Journal of mechanical design, Vol. 122, pp. $31-42$. 
[13] Srinath and Rao, 2006, Correlation to detect isomorphism, parallelism and type of freedom, Mechanism and Machine Theory, 41(6), 646-655.

[14] R. Simoni, A.P.Carboni and D. Martins, 2009, Enumeration of Kinematic Chains and Mechanisms, Proc. I MechE., Vol. 223, Part C: J Mechanical Engineering science.

[15] Ashok Dargar, Ali Hasan and R.A.Khan, 2009, Identification of Isomorphism among Kinematic Chains and Inversions Using Link Adjacency Values, IJMME, Vol.4, No.3, pp 309 - 315.

[16] Sanyal Shubhashis, 2009, Detection of Isomorphism amongst Planar Kinematic Chains using Link Joint Connectivity Table, International conference on Applied Mechanics and Machines, WASET09, Bangkok.

[17] Bedi, G.S and Sanyal S., 2010, Joint Connectivity: A new approach for detection of Isomorphism and Inversions of Planar Kinematic Chains, J. Institution of Engineers(India), Jan. 2010, Vol.90, pp $23-26$.

[18] G.S.Bedi and S.Sanyal, 2011, Modified Joint Connectivity approach for identification of topological characteristics of Planar Kinematic Chains, Proc. IMechE Vol.225, Part C: J. Mechanical Engineering Science, pp 2700 - 2717. 